\title{
Significance of Serum Uric Acid Level in Patients of Stroke with Diabetes Mellitus
}

\author{
Tanmoy W Momin ${ }^{1}$, "Pijush K Mandal ${ }^{2}$, Subhraprakash Pramanik ${ }^{3}$,Arpan K \\ Dey $^{3}$ Koushik Mandal ${ }^{1}$, Agnibha Dutta ${ }^{1}$, Saurabh Maji ${ }^{4}$, Saumyajit Ghosh ${ }^{4}$, \\ Somenath Dasgupta ${ }^{5}$ \\ ${ }^{1,3-5}$ Post-Graduate Trainee, Senior Resident, Asst. Prof., Professor and HOD, Department of General \\ Medicine, Burdwan Medical College, Burdwan, India \\ ${ }^{2-}$ Senior Resident, Department of General Medicine, ESIPGIMSR-Maniktala,Kolkata,India
}

\begin{abstract}
INTRODUCTION: Some studies have linked serum uric acid with stroke in diabetes mellitus. But it is debated. Therefore, we propose to evaluate hyperuricemia as a risk factor for stroke in patients with diabetes mellitus.
\end{abstract}

METHODS:In this cross-sectional observational study we studied 100 patients of stroke (both ischemic and hemorrhagic) with diabetes mellitus and compared with 50 controls of stroke (both ischemic and hemorrhagic) without diabetes mellitus and 50 patients of diabetes mellitus without stroke, serum uric acid levels were measured and compared using chi-square test, ANOVA, regression analysis by standard biomedical software (SPSS version 20).

RESULT: In this age and sex matched study the mean uric acid level was highest in diabetic stroke patients $(7.98 \pm 1.77 \mathrm{mg} / \mathrm{dl})$ compared to non-diabetic stroke patients $(6.34 \pm 1.51 \mathrm{mg} / \mathrm{dl})$ and it was lowest in only diabetic patients $(5.96 \pm 1.50 \mathrm{mg} / \mathrm{dl} ; p$ value $<0.001)$. And, the serum level of uric acid is significantly correlated with $F B S, P P B S$, glycated haemoglobin, and with duration of diabetes ( $p$ value $<0.05$ ).

CONCLUSION: In conclusion high serum uric acid level is associated with stroke patients with diabetes mellitus and also well correlated with blood glucose levels and duration of diabetes. So, hyperuricemia may be used as a marker of stroke with diabetes, further and larger study is needed to conclude that.

KEY WORDS: serum uric acid, hyperuricemia, stroke, diabetes mellitus.

\section{INTRODUCTION}

Stroke, both ischemic and hemorrhagic, is acommon and devastating disorder and currently one of the leading causes of mortality worldwide. Diabetes mellitus is an important risk factor of cerebrovascular accident. The worldwide prevalence of DM has risen dramatically over the past two decades more so in India. With an increasing incidence worldwide, DM will be a leading cause of morbidity \& mortality for the foreseeable future. Serum uric acid has been thought to be in humans a metabolically inert end product of purine metabolism without physiological significance (except gouty diathesis). However, serum uric acid has been recently associated with insulin resistance. ${ }^{1}$ Serum uric acid is a soluble antioxidant scavenger, ${ }^{2}$ and oxidative stress is a hallmark of tissues' hyperglycemic milieu. ${ }^{3}$ In addition, the increase in serum uric acid is a feature of the metabolic syndrome. ${ }^{4}$ Furthermore, serum uric acid may be considered as a marker of acute endothelial dysfunction, since hyperuricemia has been observed to be associated with raised endothelin levels, ${ }^{5}$ and there is evidence of uric acid involvement, via purine metabolism, in the process of thrombus formation. Some studies ${ }^{6}$ have linked serum uric acid with STROKE in diabetes mellitus. But it is debated. Therefore, we propose to evaluate hyperuricemia as a risk factor for stroke in patients with diabetes mellitus.In our present study we aimed to find out the association between stroke and hyperuricemia in diabetic patients and also the correlation of serum uric acid with stroke in patients with diabetes mellitus.

\section{MATERIALS AND METHODS}

In this cross-sectional observational study we studied 100 patients of stroke(both ischemic and hemorrhagic) with diabetes mellitus admitted in General Medicine department and compared with 50 controls of stroke(both ischemic and hemorrhagic) without diabetes mellitus and 50 patients of diabetes mellitus without stroke, conducted in a tertiary care hospital in west Bengal, India. 
Patients satisfying both inclusion and exclusion criteria designed to be appropriate for the studywere selected for this study, from January 2012 to August 2013.A case of Diabetes mellitus should meet the following criteria - Fasting blood glucose $126 \mathrm{mg} / \mathrm{dl}$ Or more OR, 2 hours plasma glucose $200 \mathrm{mg} / \mathrm{dl}$ Or more during an oral glucose tolerance test OR, Symptoms of diabetes (polyuria, polyphagia, polydipsia) with random blood glucose $200 \mathrm{mg} / \mathrm{dl}$ Or more.Inclusion criteria includes Focal neurological deficit of sudden onset that persisted beyond 24 hours with diabetes mellitus, or, Cerebral infarctions or hemorrhage documented by computed tomography or magnetic resonances imaging scan without diabetes mellitus, and, Age sex match diabetes mellitus without stroke and exclusion criteria includes Focal neurological deficit of sudden onset that lasted less than 24 hrs., Chronic renal failure, Patients on antiuricosurics and alcoholics.A thorough careful history including age, sex, duration of diabetes, H/O smoking, hypertension etc. and height, weight and blood pressure of the patients were noted. Hypertension was diagnosed when a patient had received medicine for hypertension, or had systolic blood pressure $\geq 140 \mathrm{mmHg}$ and/or diastolic blood pressure $\geq 90 \mathrm{mmHg}$ after taking 5 minutes rest. Participants were classified as non-smokers if they had smoked fewer than 100 cigarettes or 5 packs of cigarettes during their lifetime.Patients who used cholesterol lowering medication or had a total serum cholesterol level $\geq 200 \mathrm{mg} / \mathrm{dl}$ were classified as having hypercholesterolemia or dyslipidemia.FBG, PPBG measured by glucose oxidase method and $\mathrm{HbA1C}$, lipid profile measured by standard biochemical methods. Uric acid estimation by autoanalyser. Patients having uric acid more than $6.8 \mathrm{mg} / \mathrm{dl}$ is considered hyperuricemia. Independent sample T test, chi square test, ANOVA, simple regression analysis etc. were performed for result \& analysis. $\mathrm{P}$ value less than 0.05 was taken as statistically significant. All these analysis were performed using a commercially available software SPSS (20th version) on personal computer.

\section{RESULTS}

Table 1:Baseline characteristics of 3 groups

\begin{tabular}{|l|l|l|l|l|}
\hline Parameters & Stroke with diabetes & Stroke without diabetes & Diabetes only & Sig. (P value) \\
\hline Mean Age (years) & $67.14 \pm 7.76$ & $72.26 \pm 8.06$ & $68.62 \pm 9.78$ & 0.151 \\
\hline Gender & $68 \% \mathrm{M}, 32 \% \mathrm{~F}$ & $48 \% \mathrm{M}, 52 \% \mathrm{~F}$ & $58 \% \mathrm{M}, 42 \% \mathrm{~F}$ & 0.128 \\
\hline Hypertensive & $72 \%$ & $72 \%$ & $58 \%$ & 0.084 \\
\hline Smoker & $74 \%$ & $66 \%$ & $68 \%$ & 0.240 \\
\hline Dyslipidemia & $88 \%$ & $66 \%$ & $64 \%$ & 0.012 \\
\hline FBS (mg/dl) & $181.70 \pm 12.39$ & $101.56 \pm 6.02$ & $172.74 \pm 20.18$ & $<0.001$ \\
\hline PPBS (mg/dl) & $284.09 \pm 41.25$ & $127.16 \pm 4.93$ & $250.22 \pm 38.33$ & $<0.001$ \\
\hline HbA1C (\%) & $9.11 \pm 0.63$ & $4.87 \pm 0.48$ & $8.04 \pm 0.80$ & $<0.001$ \\
\hline Uric acid (mg/dl) & $7.98 \pm 1.77$ & $6.34 \pm 1.51$ & $5.96 \pm 1.50$ & $<0.001$ \\
\hline
\end{tabular}

In our study the mean age of the patients are $69.34 \pm 8.79$ years and there are $58 \%$ male patients and $42 \%$ female patients included in our study. There is no significant difference in age and gender distribution in three groups ( $p$ value $>0.05$ ). The distribution of hypertensive patient and smoker were almost similar in three study groups ( $p$ value 0.084 and 0.240 respectively) though the dyslipidemia was more commonly associated with diabetic stroke patents compared to non-diabetic stroke and only diabetic patents $(88 \%$ vs. $66 \%$ and $64 \%$ respectively, $p$ value 0.012$)$.Mean fasting blood glucose level $(181.70 \pm 12.39 \mathrm{mg} / \mathrm{dl} \mathrm{vs} .101 .56 \pm 6.02 \mathrm{mg} / \mathrm{dl}$ and $172 \pm 20.18 \mathrm{mg} / \mathrm{dl}$ respectively, p value $<0.001)$, post-prandialbloodglucose level $(284.09 \pm 41.25 \mathrm{mg} / \mathrm{dl}$ vs. $127.16 \pm 4.93 \mathrm{mg} / \mathrm{dl}$ and $250.22 \pm 38.33 \mathrm{mg} / \mathrm{dl}$ respectively, p value <0.001)andglycated hemoglobin $(9.11 \pm 0.63 \%$ vs. $4.87 \pm 0.48 \%$ and $8.04 \pm 0.80 \%$ respectively, $\mathrm{p}$ value $<0.001$ ) levels were significantly high in diabetic stroke patients compared to others. The mean uric acid level was highest in diabetic strokepatients $(7.98 \pm 1.77 \mathrm{mg} / \mathrm{dl})$ compared tonondiabetic stroke patients $(6.34 \pm 1.51 \mathrm{mg} / \mathrm{dl})$ and it was lowest in only diabetic patients $(5.96 \pm 1.50 \mathrm{mg} / \mathrm{dl} ; \mathrm{p}$ value $<0.001)$.

Table:2Simple linear regression analysis

\begin{tabular}{|c|c|c|c|c|c|}
\hline \multirow[t]{2}{*}{ Dependent Variable: Serum Uric Acid } & \multirow{2}{*}{$\frac{\text { Standardized Coefficients }}{\text { Beta }}$} & \multirow[t]{2}{*}{$\mathrm{t}$} & \multirow[t]{2}{*}{ Sig. } & \multicolumn{2}{|c|}{ 95.0\% Confidence Interval for B } \\
\hline & & & & Lower Bound & Upper Bound \\
\hline (Constant) & & -2.002 & .048 & -12.171 & -.048 \\
\hline Fasting glucose & .216 & 2.192 & .031 & .002 & .046 \\
\hline PP blood glucose & .210 & 2.339 & .022 & .001 & .014 \\
\hline HbA1C & .394 & 4.589 & .000 & .375 & .948 \\
\hline Duration of diabetes & .292 & 3.434 & .001 & .282 & 1.058 \\
\hline
\end{tabular}

Serum level of uric acid is significantly correlated with FBS, PPBS, glycated haemoglobin, and with duration of diabetes ( $\mathrm{p}$ value $<0.05$ ).

\section{DISCUSSION}


In this study we found that the mean uric acid level was highest in diabetic stroke patients $(7.98 \pm 1.77 \mathrm{mg} / \mathrm{dl})$ compared to non-diabetic stroke patients $(6.34 \pm 1.51 \mathrm{mg} / \mathrm{dl})$ and it was lowest in only diabetic patients $(5.96 \pm 1.50 \mathrm{mg} / \mathrm{dl} ; \mathrm{p}$ value $<0.001)$. Lehto $\mathrm{S}$, et.al. also observed similar findings in their study. ${ }^{7}$ Hyperuricemia has previously been described as a strong predictor of well-defined cerebrovascular complications (stroke) in a Finnish cohort ofpatients with type 2 diabetes.High uric acid level (above the median value of $>295 \mu \mathrm{mol} / \mathrm{L})(4.9 \mathrm{mg} / \mathrm{dl})$ was significantly associated with the risk of fatal and nonfatal stroke indicating hyperuricemia as a strong predictor of stroke events in middle-aged patients with NIDDM independently of other cardiovascular risk factors. ${ }^{7}$ Guan MP et.al.alsoobserved that the male type 2 diabetic patients with stroke had significantly higher mean levels of serum uric acid than simple diabetic patients. ${ }^{8}$

Hyperuricemia was associated with a significantly higher risk of both stroke incidence (6 studies; RR $1.41,95 \%$ confidence interval 1.05 and 1.76) and mortality (6 studies; RR 1.36, 95\% CI 1.03 and 1.69) in a meta-analysis (Kim SY et. al.). ${ }^{9}$ Subgroup analyses adjusting for known risk factors such as age, hypertension, diabetes mellitus, and cholesterol still showed that hyperuricemia was significantly associated with stroke incidence. ${ }^{9}$ Moderate levels of UA already appear to be associated with an increased incidence of AMI, stroke and CHF in middle-aged subjects without priorcardiovasculardisease(I. Holmeet. al.). ${ }^{10} \mathrm{~A}$ previous study reported a direct and graded relationship between UA and the risk of diabetes in the Mauritian population over 5 years (Boyko et al. 2000). ${ }^{11}$ All the three parameters, HbA1C, serum insulin and serum uric acid were found to be increased in the patients of Type 2 Diabetes Mellitus(Gill et. al. 2013). ${ }^{12}$ Serum uric acid predicts mortality in Type 2 diabetic patients regardless of gender, HbA1C, renal function and diuretic use( Ioachimescu AG et al). ${ }^{13}$ Due to the high prevalence of hyperuricemia in patients with acute stroke, and its accompanying increase in triglyceride and LDL cholesterol levels, it can be considered as a risk factor for acute stroke (Mehrpour M et al). ${ }^{14}$ SUA is more a marker of the magnitude of the cerebral infarction than an independent predictor of stroke outcome (Chiquete E et al). ${ }^{15}$ There is mounting evidence that it may also have an important role in the development of vascular conditions such as coronary heart disease, stroke and kidney disease. ${ }^{16}$ Findings demonstrate that mildly elevated serum uric acid is associated with increased burden of cerebral ischemic pathology, particularly in older adults. ${ }^{17}$ Hyperuricemia was observed as an independent risk factor of mortality in CVD and ischemic stroke in Taiwanese general population. ${ }^{18}$

\section{CONCLUSION}

In conclusion, high serum uric acid level is associated with stroke patients with diabetes mellitus and also well correlated with blood glucose levels and duration of diabetes. So, hyperuricemia may be used as a marker of stroke with diabetes, further and large scale study is required to conclude that.

\section{BIBLIOGRAPHY}

[1] To yry JP, Niskanen LK, La nsimies EA, Partanen KP, Uusitupa MIJ Autonomic neuropathy predicts the development of stroke in patients with non-insulin-dependent diabetes mellitus. Stroke. 1996;27:1316-1318.

[2] Steinberg HO, Brechtel G, Johnson A, Fineberg N, Baron AD. Insulinmediatedskeletal muscle vasodilatation is nitric oxide dependent. J Clin Invest. 1994;94:1172-1179.

[3] Suarna C, Dean RT, May J, Stocker R. Human atherosclerotic plaque contains both oxidized lipids and relatively large amounts of alpha-tocopherolandascorbate. ArteriosclerThrombVasc Biol. 1995;15:1616-1624.

[4] Lee J, Sparrow D, Vokonas PS, Landsberg L, Weiss ST. Uric acid and coronary heart disease risk: evidence for a role of uric acid in the obesityinsulin resistance syndrome: the Normative Aging Study. Am J Epidemiol.1995;142:288 -294.

[5] Selby JV, Friedman GD, Quesenberry CPJ. Precursors of essential hypertension: pulmonary function, heart rate, uric acid, serum cholesterol, and other serum chemistries. Am J Epidemiol. 1990;131:1017-1027.

[6] Wilson PWF, Garrison RJ, Abbott RD, Castelli WB. Factors associated

[7] with lipoprotein cholesterol levels: the Framingham Study. Arteriosclerosis. 1983;3:273-281.

[8] Lehto S, Niskanem L, Ronnemaa T, Laakso M: Serum uric acid is a strong predictor of stroke in patients with noninsulindependent diabetes mellitus.Stroke29:635-639, 1998

[9] Guan MP, Xue YM, Shen J, Zhou L, Gao F, Liu SQ, Li CZ. Serum uric acid in type 2 diabetic patients complicated by stroke.Di Yi Jun Yi Da XueXueBao. 2002 Jan;22(1):70-1.

[10] Kim SY, Guevara JP, Kim KM, Choi HK, Heitjan DF, Albert DAHyperuricemia and risk of stroke: a systematic review and metaanalysis.Arthritis Rheum. 2009 Jul 15;61(7):885-92.

[11] I. Holme1, A. H. Aastveit2, N. Hammar3,4, I. Jungner5 \& G. Walldius6,7Uric acid and risk of myocardial infarction, stroke and congestive heart failure in 417734 men and women in the ApolipoproteinMOrtalityRISk study (AMORIS) well Publishing Ltd Journal of Internal Medicine 266; 558-570 561.

[12] Boyko EJ, de Courten M, Zimmet PZ, Chitson P, Tuomilehto J, Alberti KG (2000): Features of the metabolic syndrome predict higher risk of diabetes andimpaired glucose tolerance: a prospective study in Mauritius. Diabetes care 23:1242-8.

[13] Gill A, Kukreja S, Malhotra N, Chhabra N. 2013 Correlation of the serum insulin and the serum uric Acid levels with the glycated haemoglobin levels in the patients of type 2 diabetes mellitus.J ClinDiagn Res. 2013 Jul;7(7):1295-7.

[14] Ioachimescu AG, Brennan DM, Hoar BM, Kashyap SR, HoogwerfBJSerum uric acid, mortality and glucose control in patients with Type 2 diabetes mellitus Diabet Med. 2007 Dec;24(12):1369-74.

[15] Mehrpour M, Khuzan M, Najimi N, Motamed MR, Fereshtehnejad SM Serum uric acid level in acute stroke patients. Med J Islam Repub Iran. 2012 May;26(2):66-72. 
[16] Chiquete E, Ruiz-Sandoval JL, Murillo-Bonilla LM, Arauz A, Orozco-ValeraDR, Ochoa-Guzmán A, Villarreal-Careaga J, LeónJiménez C, BarinagarrementeriaF,Ramos-Moreno A, Cantú-Brito C; Serum uric acid and outcome after acute ischemic stroke: PREMIER study, Cerebrovasc Dis. 2013;35(2):168-74.

[17] Edwards NL. The role of hyperuricemia in vascular disorders.CurrOpinRheumatol. 2009 Mar;21(2):132-7.

[18] Schretlen DJ, Inscore AB, Vannorsdall TD, Kraut M, Pearlson GD, Gordon B, Jinnah HASerum uric acid and brain ischemia in normal elderly adults.Neurology. 2007 Oct 2;69(14):1418-23.

[19] Chen JH, Chuang SY, Chen HJ, Yeh WT, Pan WH; Serum uric acid level as an independent risk factor for all-cause, cardiovascular, and ischemic stroke mortality: a Chinese cohort study. Arthritis Rheum. 2009 Feb 15;61(2):225-32. 